\title{
Remaja Sehat dalam Bersosialisasi
}

\author{
Alfi Noviyana, Nofita Tri Lestari, Devi Sovina \\ Email: alfinovi13@gmail.com \\ Prodi Kebidanan D III, Universitas Muhammadiyah Purwokerto, Indonesia \\ Jl. Soepardjo Roestam Km. 7, Sokaraja, Purwokerto \\ Telp. (0281) 6844252, 6844253/ Fax (0281) 637239
}

\begin{abstract}
Abstrak
Remaja yang tinggal di panti asuhan tentunya berbeda dengan remaja yang tinggal di rumah dengan memiliki keluarga yang utuh. Remaja mitra ini menjadi lebih rentan terhadap berbagai masalah, baik masalah sosial, psikologi maupun kesehatan reproduksi. Tujuan kegiatan pengabdian ini memberikan informasi dan pengetahuan yang berhubungan dengan kesehatan sosial dan berbagai resiko yang dapat dialami oleh remaja, melatih remaja untuk mencari pertolongan bila tidak dapat memecahkan masalah yang sedang dihadapi. Kegiatan pengabdian ini meggunakan metode fasilitasi. Kegiatan diawali dengan pre test dan diakhiri dengan post test. Kegiatan fasilitasi dilakukan 2 kali. Kegiatan diikuti oleh mitra dengan konsisten dan aktif. Hasil kegiatan ini ada peningkatan pengetahuan mitra tercermin dalam peningkatan nilai post test, mitra mampu menunjukkan keterampilan mengidentifikasi masalah dan kemampuan berkomunikasi interpersonal, dan mau menungkapkan pendapat. Hambatan dari kegiatan ini adalah Tim pengabdian belum mampu menjadi pendamping bagi mitra yang menghadapi masalah sosial, sehingga tim melaporkan dan mendiskusikannya dengan pengasuh panti asuhan putri, tentang temuan-temuan permasalahan yang dihadapi peserta mitra. Kesimpulan kegiatan pengabdian ini meningkatkan wawasan dan pengetahuan mitra terhadap kesehatan jiwa, pertemanan yang sehat dan tekanan pergaulan yang dapat mereka alami. Sehingga paham, apa yang harus dilakukan untuk mengatasi permasalahan psikologis yang dihadapi.
\end{abstract}

Kata Kunci: remaja; sehat bersosialisasi.

\begin{abstract}
Adolescents who live in orphanages are certainly different from teenagers who live at home with a complete family. These teenage partners are more vulnerable to various problems, including social, psychological and reproductive health problems. The purpose of this service activity is to provide information and knowledge related to social health and various risks that can be experienced by adolescents. To train adolescents to seek help if they cannot solve the problems they are facing. This service activity uses the facilitation method. The activity begins with a pre test and ends with a post test. Facilitation activities were carried out 2 times. Activities followed by partners consistently and actively. The result of this activity is an increase in partner knowledge, reflected in an increase in post test scores, partners are able to demonstrate problem identification skills and interpersonal communication skills, and are willing to express opinions. The obstacle to this activity is that the community service team has not been able to become a companion for partners who are facing social problems, so the team reports and discusses them with the caregivers of the female orphanage, about the findings of problems faced by partner participants. The conclusion of this service activity increases partners' insights and knowledge about mental health, healthy friendships and social pressures that they can experience. So that you understand, what must be done to overcome the psychological problems faced.
\end{abstract}

.Keywords: adolescents; healthy socializing. 


\section{Pendahuluan}

Sebagai makhluk sosial, manusia akan menjalin dan mempertahankan hubungan dengan orang lain, baik dalam bentuk pertemanan maupun hubungan yang melibatkan kasih sayang. Pada masa remaja, akan ada banyak hubungan yang terjalin untuk pertama kalinya dalam hidup. Oleh sebab itu, remaja harus dibekali agar dapat mengenali berbagai jenis hubungan pertemanan yang positif dengan negatif serta emosi yang muncul saat berinteraksi dengan teman perempuan dan laki-laki. Pertemanan dan kasih sayang tidak seharusnya menyakiti. Diusia remaja ketika remaja mulai mengenal berbagai pertemanan dan kasih sayang, rentan mengalami hubungan yang tidak sehat jika tidak dibekali dengan informasi yang menuntun dengan baik (Paramitha dhatu dan Anindyajati, 2013).

Masa remaja dimana merupakan saat mencoba banyak peran berbeda terkait dengan hubungannya dengan teman sebaya, keluarga, komunitas dan masyarakat, ia mengembangkan sensasi individual dirinya sendiri. Jika remaja tidak berhasil membentuk sensasi dirinya sendiri, ia akan mengalami kebingungan atau difusi peran (Kyle dan Susan, 2014).

Remaja mempunyai tugas perkembangan diantaranya mencapai kemandirian emosional dari orangtua atau figur-figur yang mempunyai otoritas, mengembangkan keterampilan komunikasi interpersonal dan belajar bergaul dengan teman sebaya atau orang lain secara individual maupun kelompok serta memperkuat self-control (kemampuan mengendalikan diri) atas dasar skala nilai, prinsip-prinsip atau falsafah hidup. (Mappiare, 2000) Dalam mencapai tugas tersebut remaja rentan dan berisiko mengalami masalah psikososial yang akan berpengaruh kesehatannya secara umum hingga mengganggu kesehatan reproduksinya. Adapun masalah tersebut antara lain tekanan pergaulan, bullying, kekerasan seksual, kehamilan, perkawinan anak, infeksi menular seksual, HIVdan AIDS, penyalahgunaan NAPZA, penyakit tidak menular, penularan penyakit.

Kesehatan remaja sangat perlu diperhatikan agar dapat menjadi penerus bagi bangsa dan negara, serta dapat menjadi pribadi yang mandiri. Sebagaimana yang telah dijelaskan dalam UU RI No 136 ayat 1 tentang kesehatan remaja yang berisi "upaya pemeliharaan kesehatan remaja harus ditujukan untuk mempersiapkan menjadi orang dewasa yang sehat dan produktif, baik sosial maupun ekonomi” (Kepmenkes, 2009).

$$
\text { Panti Asuhan Putri }
$$

Muhammadiyah Purwokerto mengasuh sekitar 38 remaja Putri yang berusia 13 -19 tahun. Dengan demikian menurut usianya ada 3 tipe remaja didalam panti tersebut. Kelompok pertama remaja usia dini dengan usia 10-13 tahun, tipe yang kedua dari mitra adalah remaja pertengahan (usia $14-16$ tahun) dan tipe yang ketiga dalam kelompok mitra ini adalah remaja akhir (usia 17 -21 tahun). Remaja yang tinggal di panti asuhan tentunya berbeda dengan remaja yang tinggal di rumah 
dengan memiliki keluarga yang utuh dan mamiliki kemampuan secara ekonomi, cukup mendapatkan dukungan secara psikologi. Remaja mitra ini menjadi lebih rentan terhadap berbagai masalah, baik masalah sosial, psikologi maupun kesehatan reproduksi. Beberapa permasalahan telah diidentifikasi dalam kegiatan pengabdian ini, terkait dengan kesehatan jiwa, sehat bersosialisasi serta memahami kerentanan dan resiko diri :

a. Mitra belum memahami tentang gangguan kejiwaan dan bagaimana mengatasinya.

b. Mitra belum mampu mengidentifikasi ketika suatu hubungan bisa dikatakan sehat atau tidak sehat, serta tindakan apa yang diambil jika mengalami hubungan yang tidak sehat.

c. Mitra belum memahani tentang konsep perundungan, tekanan pergaulan dan perilaku tawuran

Adapun tujuan program ini adalah :

a. Memberikan informasi dan pengetahuan yang berhubungan dengan kesehatan sosial dan berbagai resiko yang dapat dialami oleh remaja.

b. Melatih remaja untuk mencari pertolongan bila tidak dapat memecahkan masalah yang sedang dihadapi, mampu memahami tindakan yang dapat diambil jika mengalami hubungan yang tidak sehat.

c. Melatih remaja untuk dapat berempati dengan orang-orang disekelilingnya
Manfaat dari kegiatan ini :

a. Mitra menjadi tidak malu untuk mengakui masalah yang sedang dihadapi dan lebih berani untuk mencari pertolongan saat membutuhkannya sehingga tidak ada yang merasa sendirian dalam menghadapi berbagai tantangan hidup

b. Mitra belajar untuk berbagi, berempati dengan sesama. lebih sensitif terhadap kebutuhan orang -orang yang ada disekelilingnya.

\section{Metode}

Kegiatan pengabdian ini dilaksanakan dengan menggunakan metode fasilitasi. Fasilitasi adalah proses yang menguatkan, mendukung dan mendorong pembelajaran menggunakan berbagai teknik yang berbasis kebutuhan siswa, pengalaman nyata dan berbagai aktivitas. Fasilitasi bertujuan untuk "mempermudah" atau "membantu berjalannya sebuah proses". Dengan demikian, fasilitasi dalam konteks praktik komunitas adalah suatu proses yang bertujuan membantu mengelola aliran dan diskusi kegiatan agar berjalan dengan lancar. Tim pemgabdian berperan sebagai fasilitator (Kemenkes , 2019).

Fasilitator memandu dialog dan berupaya memaksimalkan waktu dan energi peserta dengan menjaga acara dan diskusi di jalurnya baik dalam hal waktu maupun topik. Pendekatan fasilitator memungkinkan peserta untuk memanfaatkan pengalaman kegiatan dan belajar dengan cara aktif. Metode tersebut dipilih untuk menyesuaikan dengan kelompok umur target mitra yaitu 
siswa Sekolah Menengah Pertama (SMP), Sekolah Menengah Atas (SMA) dan institusi pendidikan yang sederajat.

Adapun target luaran dalam kegiatan ini adalah meningkatnya pengetahuan dan keterampilan para mitra tentang kesehatan jiwa, pertemanan dan hubungan yang sehat dan tekanan pergaulan, terpublikasinya artikel ilmiah dari kegiatan Pengabdian masyarakat ini baik lewat kegiatan oral presentasi di Seminar ataupun publikasi dijurnal ilmiah. Adanya liflet dan modul yang dimanfaatkan oleh mitra dan dikirim ke Haki, serta pada kegiatan ini diharapkan mitra pada akhirnnya juga mampu untuk menjadi pendidik sebaya/peer educator yang dilatih dan didorong untuk menyebarluaskan pengetahuan kepada teman-teman sebaya.

\section{Hasil dan Pembahasan}

Kegiatan Bertempat Ruang Aula Panti Asuhan Putri Muhammadiyah Purwokerto. Jumlah peserta yang mengikuti kegitan pertama ada 30 dari 38 Santriwati Panti Asuhan Putri Muhammadiyah Purwokerto. Kegitan selanjutnya dihadiri 32 mitra santriwati.

Realisasi Penyelesaian Masalah :

a. Ketua dan anggota melakukan diskusi pelaksanaan pengabdian dan pembagian tugas. Menetapkan materi yang akan disosialisasikan kepada mitra. Membuat liflet dan menyusun Modul.

b. Ketua tim pengabdian dan anggota melakukan koordinasi kembali pada pihak Panti Asuhan Putri Muhammadiyah Purwokerto untuk finalisasi hari pelaksanaan. Kegiatan disepakati hari Jumat Tanggal 17 Januari 2020 pukul 16.00 WIB sampai selesai, di Ruang Aula Panti Asuhan Putri Muhammadiyah Purwokerto

c. Pada tanggal 15 Januari 2020 pelaksanaan kegiatan diadakan Breafing tim untuk teknis pelaksanaan kegiatan dan pembagian tugas.

d. Kegiatan sosialisasi pertama tentang permasalahan kesehatan remaja kesehatan jiwa pada remaja, telah dilaksanakan pada Tanggal 17 Januari setelah ashar (16.00 WIB) sampai pukul 17.30. Bertempat Ruang Aula Panti Asuhan Putri Muhammadiyah Purwokerto Jumlah peserta yang mengkuti ada 30 Santriwati Panti Asuhan Putri Muhammadiyah Purwokerto. Adapun rangkaian kegiatan yang dilakukan :

1) Memberikan salam dan sapa kepada peserta atau mitra, menyampaikan bahwa hari ini mitra akan mempelajari tentang kesehatan jiwa. Membangun suasana yang tepat untuk berdiskusi, meminta peserta untuk menyebutkan beberapa gejala orang dengan gangguan siswa. Kemudian meminta mitra untuk mengisi kuesioner, Periksa Diri ( kuesioner refleksi diri berdasarkan apa yang dirasakan dalam 30 hari terakhir).

2) Mitra mengisi kuesiner periksa diri dan menghitung skornya tanpa 
memberitahukan kepada orang lain. Setelah semua selesai, Tim menyampaikan bahwa bagi yang mendapatkan skor 8 keatas sangat disarankan untuk konsultasi pada pengasuh panti, atau guru BK disekolah atau setidaknya menceritakan masalah yang dihadapi kepada orang yang mereka percayai, seperti orangtua atau teman yang bijaksana. Tim menjelalaskan bahwa terdapat tingkat keparahan gangguan kesehatan jiwa berbeda-beda, namun setiap orang dapat berisiko menderita gangguan kejiawaan.

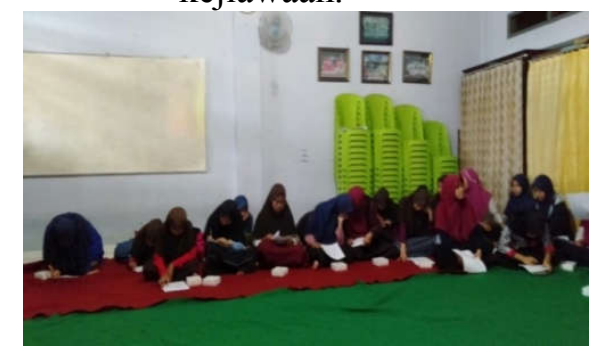

Gambar 3.1 Pengisian kuesioner deteksi diri

3) Tim meminta mitra untuk berdiskusi berpasangan dengan teman sebelahnya untuk menjawab pertanyaan apakah yang bisa menyebabkan seseorang menderita gangguan jiwa dan apa yang bisa dilakukan untuk menolongnya. Tim meminta beberapa kelompok untuk menyampaikan hasil diskusinya tanpa menilai apakah pendapatnya benar atau salah. Tim menyimpulkan dari materi dan mengajak mitra membaca 3 point penting: $\begin{array}{lrr}\text { Ganguan } & \text { jiwa adalah } \\ \text { kumpulan } & \text { gejala dari } \\ \text { gangguan } & \text { pikiran, } \\ \text { gangguan } & \text { perasaan dan } \\ \text { gangguan } & \text { tingkah laku } \\ \text { yang } & \text { menimbulkan } \\ \text { penderitaan } & \text { dan } \\ \text { tergangguanya } & \text { fungsi } \\ \text { sehari-hari } & \text { seseorang }\end{array}$

sehingga memerlukan pertolongan secara medik. Orang dengan gangguan jiwa dipicu oleh fakto biologis, faktor psikologis dan faktor sosial . Bila menghadapi masalah, jangan dipendam sendirian. Bicarakan dengan orang lain yang dipercaya dan dekatkan diri kepada Allah SWT.

4) Tim mengakhiri sesi kegiatan dengan mengucapkan terimakasih kepada semua mitra karena telah hadir di sesi dan berpamitan. Sambil mengingatkan siswa untuk mencari pertolongan bila mengalami masalah dan memberikan dukungan bagi teman yang membutuhkannya.

e. Kegiatan pertemuan yang ke2 dilaksanakan pada 14 Februari 2020. Pada pertemuan ini Tim dan mitra akan membahas tentang pertemanan, hubungan yang sehat dan resiko diri. Pada akhir kegiatan ini diharapkan mitra dapat mengenali hubungan yang sehat dengan teman sebaya dan memiliki gambaran mengenai hubungan yang sehat dan menjauhi hubungan yang tidak sehat dan cenderung berdampak buruk. 
Keterampilan hidup yang dikembangkan membangun hubungan inter-personal yang sehat, berfikir kritis antara dinamika dengan solidaritas dan tekanan pergaulan, serta mampu berempati terhadap kekurangan orang lain yang bisa menjadikan penyebab seseorang mengalami perundunngan.

Adapun rangkaian kegiatan yang dilaksanakan pada petemuan tersebut :

1) Mengajak mitra untuk menuliskan dan menyampaikan katakter teman seperti apa yang diharapkandan yang disukai

2) Menjelaskan hubungan yang sehat, menekankan bahwa setiap orang berhak untuk diperlakukan dengan baik dan memiliki hubungan yang sehat, sebuah hubungan pertemanan atau persahabatan harus dibangun dari rasa saling menghargai dan mendukung dan hubungan yang tidak sehat harus dihindari.

3) Dilanjutkan topik selanjutnya tentang tekanan pergaulan. Meminta mitra untuk menuliskan hanya hal yang baik atau yang dikagumi tentang setiap teman satu kamar dipanti. Kemudian mengajak peserta untuk membayangkan jika situasi yang terjadi adalah sebaliknya, yakni perundungan. Menjelaskan sekilas bentuk dan dampak dari perundungan, mengajak peserta atau mitra bagaimana cara menghadapi dan mencegah perundungan dilingkungan sekitar .
4) Mendiskusikan topik terakhir tentang tawuran remaja. menanyakan bagaimana kiat peserta untuk tidak terpengaruh pada tawuran remaja. menjelaskan bahwa tawuran disebabkan kuatnya tekanan pergaulan bukan bentuk solidaritas atau kekompakan sesama teman.
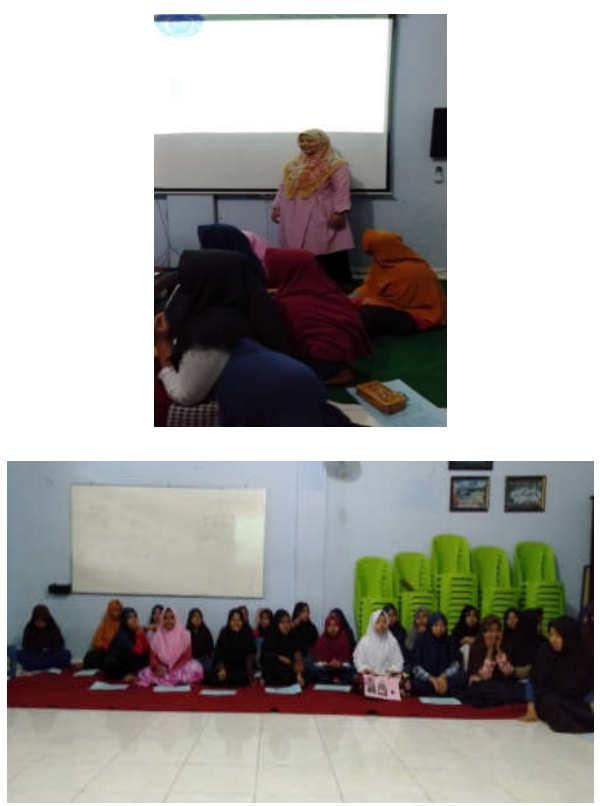

Gambar 3.2 Diskusi dan penyampaian materi

Pada akhir sesi pertemuan Tim pengabdian memberikan kuesiner post tes materi yang telah dibahas selama 2 kali pertemuan.

\section{Hasil Kegitan}

Kegiatan terlaksana sesuai dengan tujuan. Indikator keberhasilan program ini terlihat dari peserta yang konsisten dari awal hingga akhir program. Adapun evaluasi hasil kegiatan :

a. Terdapat peningkatan pengetahuan mitra yang berhubungan dengan kesehatan sosial dan berbagai 
resiko yang dapat dialami oleh remaja. Hal ini terlihat dari keaktifan diskusi para peserta dan hasil kuesioner pra -pasca kegiatan yang dibagikan Tim kepada para peserta (mitra).

Tabel. 5.1 Hasil evaluasi kuesioner pengetahuan pra dan pasca kegiatan

\begin{tabular}{cccc}
\hline No & $\begin{array}{c}\text { Klasifikasi } \\
\text { Penilaian } \\
\text { Kuesioner }\end{array}$ & $\begin{array}{c}\% \\
\text { Pencapaia } \\
\text { Pra - } \\
\text { Kegiatan }\end{array}$ & $\begin{array}{c}\text { Kegiatan } \\
\end{array}$ \\
\hline 1 & Rendah & $79 \%$ & $30 \%$ \\
2 & Sedang & $21 \%$ & $40 \%$ \\
3 & Tinggi & $0 \%$ & $30 \%$ \\
\hline
\end{tabular}

b. Pada kegiatan pelatihan, mitra mampu mengidentifikasi tanda gangguan kejiwaan, bersedia mencari pertolongan bila tidak dapat memecahkan masalah yang sedang dihadapi, mampu memahami tindakan yang dapat diambil jika mengalami hubungan yang tidak sehat.

c. Kegiatan diskusi saling berpasangan, saling mengungkapkan pendapat dan isi hati, menjadikan mitra lebih berempati dengan orang-orang disekelilingnya.

Adapun target luaran yang telah terlaksana bertambahnya pengetahuan dan wawasan para mitra serta diharapkan mitra dapat menjadi pendidik sebaya (peer educator), tersusunnya liflet dan modul materi. Sedangkan luaran yang berproses pembuatan artikel ilmiah dari hasil kegiatan IbM ini yang akan dikirim ke jurnal Pengabdian Harapan Ibu Pekalongan edisi Bulan Agustus 2020. Begitu pula untuk Haki produk pengabdian ini yaitu Modul untuk Remaja sedang proses didaftarkan.

Hambatan dari kegiatan ini adalah Tim pengabdian belum mampu menjadi pendamping bagi mitra yang menghadapi masalah sosial, sehingga tim melaporkan dan mendiskusikannya dengan pengasuh panti asuhan putri, tentang temuan-temuan permasalahan yang dihadapi peserta mitra, sehingga tim tidak menangani permasalahn peserta mitra secara langsung.

Kualitas sumberdaya manusia secara umum dapat pula dicerminkan dengan suatu indeks pembangunan manusia atau Human Development Index (HDI. Indeks tersebut mengisyaratkan perlunya perhatian untuk meningkatkan kualitas manusia Indonesia. Kualitas manusia tersebut menjadi sangat penting sebagai pertanda keberhasilan pembangunan. Kualitas remaja pun menjadi penting karena merupakan bagian dari kualitas sumberdaya manusia keseluruhan. Bentuk kualitas remaja secara khusus yang merupakan aspek penting sebagai pendorong peningkatan kualitas sumberdaya manusia. kualitas remaja dapat diketahui berdasarkan kualitas fisik, kualitas akal, dan kualitas kalbu (Suksmadi, ,2009)

\section{Kesimpulan}

Program IbM yang dilaksanakan di Panti Asuhan Muhammadiyah meningkatkan wawasan dan pengetahuan mitra terhadap kesehatan jiwa, pertemanan yang sehat dan tekanan pergaulan yang dapat mereka alami. Sehingga paham, apa yang harus dilakukan untuk 


$$
\begin{aligned}
& \text { mengatasi permasalahan } \\
& \text { psikologis yang dihadapi. } \\
& \text { Adapun saran dari tim } \\
& \text { pengabdian setelah } \\
& \text { melaksanakan } \\
& \text { pengabdian ini adalah : } \\
& \text { a. Dibentuk kelompok kakak } \\
& \text { dan adik asuh dipanti, } \\
& \text { sehingga diantara hubungan } \\
& \text { inter-personal diantara } \\
& \text { santriwati di panti lebih erat } \\
& \text { terjalin. } \\
& \text { b. Lebih sering diselenggarakan } \\
& \text { kegiatan dipanti yang dapat } \\
& \text { mendorong santriwati untuk } \\
& \text { dapat mengungkapkan } \\
& \text { permasalahan sosial yang } \\
& \text { dihadapi. }
\end{aligned}
$$

\section{Daftar Pustaka}

[1] Ignatius Suksmadi., Ujang Sumawan.. Ali Khomsan, Hartoyo. Kualitas Remaja di Kabupaten Banyumas. Jur Ilm.Kel dan Kons Vol 2 (1) : pp.154-163, 2009.

[2] Kep.Men.Kes. UndangUndang Kesehatan dan Rumah Sakit. Yogyakarta: Nuha Medika, 2009.

[3] Kementerian Kesehatan RI, Kementerian Pendidikan dan Kebudayaan RI, Kementerian Dalam Negeri, dan Kementerian Agama, Sight and Life dan SEAMEO RECFON bersama UNICEF. Aksi Bergizi Hidup Sehat Sejak Sekarang Mejadi Remaja Kekinian. Jakarta: Direktorat Gizi Kemneks RI, 2019.
[4] Kyle, T. \& Susan, C. Buku Ajar Keperawatan Pediatri, Ed. 2, vol. 1. Jakarta: EGC, 2014.

[5] Mappiare, A., Psikologi Remaja, Surabaya: Usaha Nasional, 2000.

[6] Paramitha dhatu, Anindyajati. Status Remaja Akhir, Character, vol 1 (2). pp.1-6, 2013. 